\title{
MODERNIDAD Y POSTMODERNIDAD EN EL FEMINISMO CONTEMPORÁNEO
}

\author{
CRISTINA GUIRAO MiRÓN \\ Universidad de Murcia
}

Recibido: $25 / 01 / 2010$

Aceptado: 30/04/2010

\section{Resumen}

El artículo analiza dos críticas fundamentales del pensamiento feminista a la modernidad: la separación de los espacios privado/público y el universalismo normativo. La separación de espacios privado/público tiene su origen en la modernidad, se consolida tras la Revolución Industrial y en nuestras sociedades, hoy, es la causa de la desigualdad estructural de los géneros. El universalismo normativo, de raíz deontológica, constituye la crítica más importante de la postmodernidad al proyecto ilustrado.

Palabras clave: ilustración, postmodernidad, igualdad, diferencia, universalismo normativo, espacio privado y espacio público.

\begin{abstract}
«The article criticizes two basics points of Modernity: the separation between private space/public sphere and normative universalism.

The separation between spaces has its origins in Modernity and it is the cause of gender inequality nowadays. The normative universalism is the most important criticism of Postmodernism to the Enlightened Thought.»
\end{abstract}

Keywords: enlightenment, postmodernism, equality, difference, normative universalism, private space / public sphere. 



\section{Espacio privado/espacio público}

Habermas en su obra Teoría de la acción comunicativa ${ }^{1}$ sostiene que el paso a las sociedades modernas se define por la configuración de dos estructuras diferenciadas: sistema y mundo de la vida. El sistema tiene como función la reproducción material de las sociedades y sus instituciones son la economía capitalista y el Estado; el mundo de la vida tiene como función la reproducción simbólica y lo integran la familia y la esfera pública, Öfentlichkeit, como espacio de participación y debate político

Esta escisión del mundo de la vida en espacio privado -ámbito de la familia- y espacio público -lugar del trabajo productivo y del reconocimiento social-, se consolida genéricamente a medida que el capitalismo se desarrolla y avanza. Las mujeres son apartadas de la vida económica y confinadas en su «lugar natural», el hogar y la familia; los hombres, en cambio, se adscriben al mundo de la producción.

Habermas, en una obra posterior, Historia y crítica de la opinión pública ${ }^{2}$, rastrea el origen de los conceptos privado/público. El análisis etimológico de

1. Jürgen Habermas, en su obra: Teoría de la acción comunicativa. Madrid, Taurus, 1987, mantiene que en la modernidad se separan algunas funciones de reproducción material, como el trabajo, de las funciones de reproducción simbólica, como por ejemplo el cuidado de niños. La reproducción material está en manos de instituciones especializadas como la economía y el Estado, que están integradas en el sistema, en tanto que la reproducción simbólica forma parte de la esfera privada, que Habermas conceptualiza como mundo de la vida. De este modo, las sociedades modernas «desconectan» o separan lo que Habermas considera que son dos aspectos de la sociedad distintos, aunque previamente indiferenciados: sistema y mundo de la vida.

2. A pesar de la reiterada crítica de «deficiencias empíricas» en la tesis habermasiana de cómo surge históricamente el concepto de opinión pública, ésta es sobradamente interesante. Sostiene Habermas en la citada obra que con el ascenso político de la burguesía a través de instituciones como el parlamento, la prensa o los clubs literarios y políticos, hacia finales del siglo XVIII se desarrollada en Alemania una publicidad pequeña, entiéndase un reducido público lector formado e informado, que discute críticamente, y a la par que se incrementa el número de lectores, crece el número de periódicos, librerías, bibliotecas de préstamo, sociedades de lectura, casinos... que practican formas de sociabilidad igualitaria, libertad de discusión, decisiones por mayoría, en suma, el ejercicio de la racionalidad. Todo ello creó un espacio público discursivo con creciente influencia política que dio origen a la esfera pública, donde creció y se desarrolló el concepto de

Feminismo/s 15, junio 2010, pp. 221-234 
privado y público nos lleva hasta Grecia. En las pequeñas ciudades estado griegas, la esfera de la polis, ciudad o espacio común al ciudadano, estaba claramente diferenciada del oikos, la casa. El oikos era la unidad básica de la sociedad griega e incluía al cabeza del familia, generalmente el varón de mayor edad, a su familia: mujeres y niños, y a los esclavos. Todos ellos constituían el oikos o espacio privado de lo doméstico. En la sociedad griega la vida pública bios políticos sucede en el agora (plaza), tiene su fundamento en la conversación lexis y el en diá-logo, dia (a-través) logos (palabra, discurso). El espacio privado lo constituye la casa, oikos, en ella se realiza la reproducción de la vida, el trabajo de los esclavos y el servicio de las mujeres. La sociedad griega, como sabemos, se fundamenta en una economía esclavista de orden patriarcal.

A la luz de la publicidad todo se manifiesta tal como es, todo se hace a todos visible. En la conversación entre ciudadanos fluyen las cosas hacia el lenguaje y ganan forma; en la disputa entre iguales sobresalen los mejores y ganan su esencia: la inmortalidad de la fama. Así como la necesidad vital y el mantenimiento de lo necesario para la vida están pudorosamente ocultos tras los límites del oikos, así también ofrece la polis el campo libre para la mención honorífica: los ciudadanos trafican como iguales con iguales (homoioi), pero todos procuran la preeminencia (aristoiein). Las virtudes, cuyo catálogo codificó Aristóteles, se preservan tan sólo en la publicidad, allí encuentran reconocimiento ${ }^{3}$.

Esta separación de los dos ámbitos y las funciones estructurales atribuidas a cada uno han sobrevivido hasta nuestros días. Están en el Derecho Romano, Res publica, y vuelven a adquirir notoriedad jurídica, sostiene Habermas, con el nacimiento del Estado Moderno. Si en la Edad Media ambas esferas están inextricablemente unidas, no hay separación posible entre ambas, pues ambas esferas están adheridas a la tierra y dependen del señor feudal; en la Edad moderna con el nacimiento del Estado acabaran finalmente disociándose. La

opinión pública tal y como lo conocemos hoy. En estas sociedades pudieron ensayarse las normas de la igualdad política de la sociedad futura y produjeron una politización de la vida social con el consiguiente auge de la prensa de opinión. Todo esto formó una red expansiva de comunicación pública que llegó hasta mediados del siglo XIX, origen de la sociedad de masas, momento en el que este concepto de opinión pública pasa a ser considerado opinión de masas, «arrancada al contexto funcional de las instituciones políticas y despojada de su carácter de opinión pública pues ahora pasa a ser producto de un proceso de comunicación en el seno de la sociedad de masas no vinculado ya al ejercicio de la racionalidad, esto es, ni a los principios de la discusión pública ni a los de la dominación política». HABERMAS, Jürgen. Historia y crítica de la opinión pública. Barcelona, Editorial G. Gili. 1999, p. 265.

3. HABERMAS, Jürgen. Op. cit, pp. 43-44. 
aparición de un incipiente capitalismo, el tráfico de mercancías y noticias -fase ésta en la que se forman las economías nacionales y territoriales y en la que Habermas sitúa el nacimiento del concepto opinión pública-; el Estado moderno y su organizaciones burocráticas acabarán finalmente por separarlas.

Una cuestión muy importante para la teoría feminista contemporánea es la interacción entre estas esferas y su desarrollo histórico en Occidente. Concretamente, la forma en que dicha dicotomía estructura la vida de las mujeres, la división sexual del trabajo y el desarrollo del capitalismo. La escisión o dicotomía funcional habermasiana entre esfera pública y privada es el tema de fondo de las críticas feministas a la institucionalización de lo privado y de lo público.

De entrada la primera crítica en la que estarían de acuerdo Pateman, Fraser, Young y Benhabid ${ }^{4}$ es que la teoría habermasiana, en su punto central de la distinción sistema/mundo de la vida, no cuestiona la división sexual que ella misma estructura, por tanto institucionaliza el sometimiento de las mujeres. Y aunque ciertamente, la interpretación habermasiana da un paso más allá del androcentrismo marxista de interpretación del trabajo, pues al menos reconoce la actividad de las mujeres en el espacio privado de la familia, al que atribuye la función de reproducción simbólica; aún así decimos, focaliza mal la cuestión de género y puede dar lugar a la legitimación ideológica de los dos espacios.

Consideramos que en este aspecto la división categorial de Habermas entre instituciones del sistema y del mundo de la vida es un espejo fidedigno de la separación institucional entre familia y economía oficial, el hogar y el puesto de trabajo pagado, de las sociedades capitalistas dominadas por el varón ${ }^{5}$.

El trabajo doméstico y de los cuidados, que se realiza en la esfera privada, tiene entre otras funciones la educación, el cuidado y la socialización de los hijos, por ello Habermas lo integra bajo el concepto mundo de la vida. El trabajo productivo, en cambio, asalariado, lo integra en el sistema. Esta distinción en el capitalismo clásico o moderno legitima la división sexual del trabajo ${ }^{6}$.

4. BENHABiB, Seyla y CORNELLA, Drucilla. Teoría feminista y teoría crítica. Valencia, Edicions Alfons el Magnánim. 1990.

5. FRASER, Nancy.«¿Qué tiene de crítica la teoría crítica?» en Benhabib, Seyla y Cornella, Drucilla. Op cit., p. 60.

6. Y el capitalismo del bienestar, en nuestras sociedades, hoy, legitima que el problema de la conciliación vida familiar y laboral sea exclusivamente un asunto de mujeres, que, hoy en día, habiten los dos espacios: el espacio público o productivo y el privado, doméstico y reproductivo.

Feminismo/s 15, junio 2010, pp. 221-234 
Carole Pateman ${ }^{7}$ denunció la existencia de un contrato implícito y previo al contrato social, el contrato sexual, por el cual a las mujeres se les asignaba la esfera privada y quedaban excluidas de la esfera pública, el lugar de la universalidad, el normativismo y la voluntad general; frente al espacio privado de las necesidades, los deseos y los afectos, al que se adscribió por afinidad a las mujeres. Es por ello que las mujeres que quieran verse incluidas en el espacio público han de pagar el precio de verse reducidas a ser como esos individuos abstractos y descorporeizados, despojados de todos los rasgos de una identidad de género.

Una segunda crítica a la concepción habermasiana, vendría por la ausencia de corporalidad en el concepto de esfera pública. Nancy Fraser ${ }^{8}$ señala que el modelo de esfera pública de Habermas es racionalista y privilegia el discurso racional sobre modos de expresión publica más evocativos y retóricos, pero sobre todo, el modelo habermasiano es excluyente, pues la red de cafés, casinos y club de debates que actuaron como autopistas de la comunicación y de la racionalidad dialógica, que dieron lugar a la aparición del concepto de opinión pública y acabaron institucionalizando la esfera pública como Res publica, lugar de los asuntos políticos, tenía una praxis y un ethos propias de una élite masculina.

Precisamente, una de las críticas más interesantes de Nancy Fraser ${ }^{9}$ a la teoría crítica habermasiana, viene porque en esta institucionalización de la separación de espacios privado/público, el Estado asume como natural la división sexual del trabajo. Afirma Habermas que en el paso del capitalismo moderno al capitalismo del bienestar se da una progresiva colonización del mundo de la vida por el sistema, en términos liberales, una intromisión del Estado en los asuntos familiares, domésticos o privados de los ciudadanos. Esta permeabilidad o colonización entre el sistema y el mundo de la vida que sucede en el capitalismo del bienestar es visible o se materializa en la introducción de medios burocráticos que gestionan nuestra vida familiar y laboral, a través de medidas de bienestar social relacionadas con la salud, los cuidados, la familia, la educación, la maternidad, la paternidad, el estado civil o la relación entre la vida familiar y laboral. La consecuencia más reiterada por Habermas de esta colonización, es la relación de clientelismo que el individuo establece en el capitalismo de bienestar con el Estado, frente a la relación de ciudadanía que el individuo ejercía en el capitalismo clásico de la modernidad. En el capitalismo de bienestar, afirma Habermas, con la pérdida de la ciudadanía, los

7. Pateman, Carole. El contrato sexual. Barcelona, Anthropos, 1995.

8. Fraser, Nancy. Op. cit. pp. 50-59.

9. Op. cit., pp. 78-88. 
contextos comunicativos se pierden, se pierde la reproducción simbólica y las identidades se ven amenazadas ${ }^{10}$.

Pero Habermas, como reitera el pensamiento feminista, olvida en sus conclusiones el subtexto de género. Así, por ejemplo, no tiene en cuenta que los roles de consumidor y cliente que canalizan en el capitalismo de bienestar la relación entre el Estado y el ciudadano, estos roles, decimos, son casi exclusivamente ejercidos por las mujeres y la población dependiente, con la consiguiente pérdida de ciudadanía que este ejercicio conlleva. Es decir, una vez más, el capitalismo de bienestar en sus programas de atención a la ciudadanía, tiene una doble red, dos tipos de programas básicos: «los masculinos», dirigidos a la participación primaria del trabajo asalariado y que da derecho a todo tipo de prestaciones y servicios; $\mathrm{y}$ los «femeninos», destinados a ayudar allí donde ha habido un «fallo en el sistema», allí donde no hay un varón sustentador y la mujer no realiza un trabajo asalariado que es el único trabajo que reconoce el Estado de bienestar. Ahora bien, si la mujer trabaja, el Estado de bienestar se ve en la necesidad de proteger a niños y familias de madres trabajadoras, mediante la multiplicación de permisos de maternidad, excedencias, reducciones de jornadas, ayudas directas a la maternidad, etc. que convierten al Estado de bienestar en un gran "patriarcado público» y a la mujer en la principal clienta de sus servicios, haciendo de ella ciudadana de segunda categoría a la que el patriarcado público ha de proteger de las propias estructuras de desigualdad, división sexual del trabajo, que él mismo crea.

Así las cosas, sostiene Fraser en su crítica a Habermas, las medidas del Estado de bienestar tienen un aspecto positivo pues reducen la dependencia de la mujer del varón, pero sustituyen la dependencia del hombre por la del Estado, del patriarcado privado al patriarcado público. Un ejemplo claro de cómo el Estado de bienestar algunas veces reproduce los estereotipos de género es, precisamente, la Ley de Conciliación Vida Laboral y Familiar (Ley 39/1999), que multiplica permisos, reducciones de jornada, excedencias..., para sellar a la mujer en el espacio privado, o en el mejor de los casos, para conciliar ambos espacios: privado y público, vida familiar y laboral, olvidando que la conciliación de ambos espacios no es sólo un asunto de mujeres, de "pobres madres trabajadoras» a las que hay que ayudar, sino de corresponsabilidad de ambos géneros ${ }^{11}$.

Concluyendo, la teoría feminista pretende la instauración de un nuevo espacio público heterogéneo, que transcienda la clásica división liberal entre

10. HABERMAS, Jürgen. Teoría de la acción comunicativa. Madrid, Taurus, 1987.

11. El permiso de paternidad en España es de 2007 y aparece con la Ley 3/2007 para la Igualdad Efectiva de Mujeres y Hombres. 
el ámbito privado y público, un espacio en donde las distintas diferencias puedan encontrar su acomodo, su reconocimiento público. Se trata, pues, de «ilustrar la ilustración», repensar las trampas de la ilustración que remiten a la distinción última entre privado y público.

\section{El principio de universalidad}

El paso de la modernidad a la postmodernidad viene marcado por la ruptura con el mito universalista de la razón ilustrada. «El buen sentido (sentido común) es la cosa mejor repartida del mundo», así comienza Descartes su Discurso del método; la razón es común a todos los hombres, por tanto, debemos ponernos de acuerdo en los asuntos fundamentales, pues a todos se nos presupone la capacidad de razonar para alcanzar la verdad y el consenso. La Ilustración se abrió con el debate sobre la emancipación de las personas, superación de la minoría de edad política a la que la humanidad estaba sometida en el orden feudal, y la declaración de igualdad de todos los hombres. «Atrévete a pensar», reza otra gran divisa de la ilustración, enalteciendo al universalismo del razonamiento, con la esperanza de que el uso de esta capacidad, común a la especie humana, permita el progreso de la misma hacia algo mejor, pues este es el fin de la naturaleza humana, según Kant: el progreso asintótico hacia la «paz perpetua».

El paso del optimismo ilustrado a la ingravidez postmoderna viene marcado por la imposibilidad histórica de realización de estos grandes proyectos. Emancipación, equidad y progreso son cuatro aspectos de la modernidad que no han concluido; la razón ilustrada y la racionalidad práctica no han hecho posible la libertad fuera de los ámbitos del mercado, la perdida de solidez y gravedad de los ideales fundamentales de la modernidad y de la razón ilustrada es evidente: «todo lo sólido se desvanece en el aire».

En este tránsito de la modernidad a la postmodernidad, el principio universalista y normativo de la razón ilustrada, el a priori universal y necesario para crear nuevas sociedades, pierde su fuerza social. Esta debilidad del universalismo en la postmodernidad es evidente en la secularización del Estado, la radicalización de la libertad individual, la sacralización de la verdad relativa frente a la verdad colectiva, la universalización de lo singular. En definitiva, el cuestionamiento del principio de universalidad.

El universalismo normativo de la razón ilustrada será el flanco de las críticas postmodernas al pensamiento ilustrado. Precisamente, desde el feminismo postmoderno las criticas a la ilustración, no sólo vienen por el lamentable error histórico de haber olvidado incluir a las mujeres en su principio de universalidad, «Todos los hombres (léase hombre en sentido genérico) son 
iguales», sino también, porque este principio de universalidad enfoca una forma de categorizar el mundo en masculino, obviando a la mujer y a otras minorías. El sustantivo «hombre» se refiere al hombre blanco, heterosexual y judeocristiano. El discurso feminista postmoderno aboga por una lucha contra el universalismo racional, político y moral que reprime las diferencias y que pretende constituirse en el concepto único, representativo y con carácter normativo en el ámbito político, moral, epistemológico o genérico. Autoras como S. Benhabid ${ }^{12}$, C. Pateman ${ }^{13}$ o Iris Marion Young ${ }^{14}$, independientemente de sus propias diferencias teóricas, coinciden en las críticas a los planteamientos holistas de la ilustración.

Las teorías morales universalistas de la tradición occidental desde Hobbes hasta Rawls son sustitucionalistas en el sentido de que el universalismo que defienden es definido subrepticiamente al identificar las experiencias de un grupo especifico de sujetos como el caso paradigmático de los humanos como tales. Estos sujetos invariablemente son adultos blancos y varones, propietarios o al menos profesionales. Quiero distinguir el universalismo sustitucionalista del universalismo interactivo. El universalismo interactivo reconoce la pluralidad de modos de ser humano, y diferencia entre los humanos, sin inhabilitar la validez moral y política de todas estas pluralidades y diferencias. Aunque está de acuerdo en que las disputas normativas se pueden llevar a cabo de manera racional, y que la justicia, la reciprocidad y algún procedimiento de universalizabilidad son condiciones necesarias, es decir son constituyentes del punto de vista moral, el universalismo interactivo considera que la diferencia es un punto de partida para la reflexión y para la acción. ${ }^{15}$

La distinción de Benhabid entre universalismo sustitucionalista ${ }^{16}$, normativo, y universalismo interactivo que pretende el reconocimiento de las particularidades, de la pluralidad, nos lleva de nuevo a la critica fundamental del feminismo postmoderno al proyecto ilustrado, a saber: integrar las diferencias supone la generalización de todos en un supuesto «sujeto normal, racional» en un «individuo universal, formal», que es el canon respecto del cual debe

12. Benhabib, Seyla y CoRnella, Drucilla. Op. cit.

13. Pateman, Carole. «Críticas feministas a la dicotomía público/privado» en Castells, Carme (coord.), Perspectivas feministas en teoría política. Barcelona, Paidós, 1996.

14. YounG, Iris Marion. «Imparcialidad y lo cívico público» en Benhabib, Seyla y Cornella, Drucilla. Op. cit., pp. 90-117.

15. BENHABID, Seyla. Op. cit., p. 127.

16. Benhabid usa el concepto universalismo sustitucionalista para representar el sujeto ontológico kantiano, dueño de la razón, centro de la historia, sujeto que protagoniza el proceso de la Modernidad. Modernidad que según Habermas tiene como principio determinante la Razón centrada en el Sujeto, una razón objetivante, homogeneizadora, totalizadora y controladora como la analizaría su maestro Adorno en los años cincuenta, en Dialéctica de la ilustración. Madrid, Trotta, 1998.

Feminismo/s 15, junio 2010, pp. 221-234 
ser enjuiciado cada cual. Podemos distinguir dos frentes de oposición feminista postmoderna a este universalismo, un frente moral y un frente político ${ }^{17}$.

Desde el ámbito moral, el pensamiento feminista de la diferencia denuncia como ilusorio y opresivo, la construcción de una instancia superior de raíz moral, independientemente de la realidad empírica, el llamado point of view moral de John Rawls, con sus premisas de «universalidad» e «imparcialidad». Asumiendo que, poner en cuestión el ideal de imparcialidad lleva a cuestionar la posibilidad misma de la teoría moral, el feminismo postmoderno, aún así, considera que esta imparcialidad da como resultado una oposición entre razón y deseos, que se sitúa en un punto de vista ideal e irreal, en una especie de nave espacial contrafáctica; una situación de razonamiento que extirpa a la gente de su verdadero contexto de toma de decisiones morales en vivo.

[...] Llevándolos a una situación en la que no podrían existir. Tal y como argumenta Michael Sandel, el ideal de imparcialidad requiere la construcción de un yo abstraído del contexto de cualquier persona real: el yo deontológico no está comprometido con ningún fin particular, ni tiene historia particular, ni pertenece a ninguna comunidad ni tiene cuerpo ${ }^{18}$.

Frente a ese yo imparcial, universal y deontológico el feminismo postmoderno propone un yo anclado en la vivencia de los hechos y fenómenos concretos, un yo con necesidades y deseos; pasado, historia e identidad.

En segundo lugar y desde el ámbito político, la razón normativa moderna deja fuera de esta esfera a todo aquello que pueda amenazar la fundamentación de la comunidad política con particularidades o diferencias que no puedan ser subsumidas bajo el principio de universalidad. Así, la especificidad de los cuerpos, los deseos, las diferencias de raza o cultura, la ambigüedad y mutabilidad del sentimiento... queda fuera del reino de lo universal. Por ello, la insistencia feminista por sacar a la luz «las diferencias» del ámbito privado al público se relaciona directamente con la dualidad igualdad/diferencia y el carácter esencialmente encubridor del principio de igualdad liberal.

La divisa de mostrar las diferencias pretende la reafirmación de una identidad amenazada bajo el principio de igualdad formal. O de una identidad construida socialmente bajo la categorización androcéntrica de los géneros; el llegar a ser mujer interpretando el rol de género que el patriarcado impone a la mujer bajo el principio formal y universal de que ser mujer significa ser así. Por ello, y como hemos comentado anteriormente, el Estado de bienestar reproduce con frecuencia el universalismo de los estereotipos de género,

17. VAllespín, Fernando. «Igualdad y diferencia» en Mate, Manuel Reyes (coord.): Pensar la Igualdad y la diferencia. Madrid, Ed. Visor, 1995.

18. YOUNG, Iris Marion. Op. cit. p. 94. 
cuando en sus políticas públicas contempla medidas paternalistas para ayudar a las mujeres. Esto le ha llevado a afirmar a D. L. Rhode que «demasiado a menudo el derecho de igual protección moderno ha tratado como diferencias inherentes y esenciales a lo que es cultural y contingente» ${ }^{19}$.

Obviamente la defensa de una filosofía de la identidad, sea femenina o de otras minorías, es un combate contra el pensamiento que expulsa de la realidad a aquellas particularidades que no pueden ser aprehendidas por un sistema de pensamiento racional absoluto.

Ahora bien, sin acceder al espacio público no se ven las particularidades lesionadas. Así las cosas, el feminismo ve esencial para la liberación de las mujeres renegociar el tipo de contrato con el Estado de Bienestar y reconstruir autónomamente las identidades psicosociales. Definir un yo que no se agote en los roles que construyen socialmente la identidad, ni aceptar estos roles sin un detenido análisis crítico. Por ello, para el movimiento feminista, el primer paso es definir cuáles son las diferencias opresivas que se interponen en el camino hacia la emancipación. Precisamente, desde el pensamiento alemán contemporáneo, Habermas ${ }^{20}$ aborda este tema, el problema suscitado por quienes abogan por una mayor presencia pública de sus identidades amenazadas. Este problema pasa, sostiene Habermas, por un esquema de democracia deliberativa que conecte el principio de autonomía individual con el de autonomía pública. Bajo el paradigma habermasiano, Benhabib ${ }^{21}$ llega a la misma conclusión. Esta autora parte de la crítica a la construcción rawlsiana del «punto de vista moral», de una persona sin cuerpo, inmaterial, sin contexto, un «yo general y abstracto» cuya construcción tipológica remite con facilidad a un principio universalizador de la justicia. Esta dessustanciación de la subjetividad impide incorporar al punto de vista moral la perspectiva del otro concreto, las diferencias y las particularidades. No se puede abstraer un grupo de personas porque no hay personas fuera de su especificidad, del empirismo de su historia concreta.

El punto de vista del otro generalizado nos demanda considerar a todos y cada uno de los individuos como seres racionales, con los mismos derechos y deberes que desearíamos concedernos a nosotros mismos. Al asumir este punto de vista hacemos abstracción de la individualidad y la identidad concreta del otro. Suponemos que el otro, al igual que nosotros mismos, es un

19. RHODE, Deborah L. Justice and Gender. Cambridge, Mass. Harvard University Press, 1989 , p. 81.

20. HABERMAS, Jürgen. Facticidad y validez. Sobre el derecho y el Estado democrático de derecho en términos de teoría del discurso. Madrid, Trotta, 2005.

21. BENHABIB, Seyla. "El otro generalizado y el otro concreto: la controversia Kohlberg-Gilligan y la teoría feminista» en Benhabib, Seyla y Cornella, Drucilla, Op. cit. pp. 120-149.

Feminismo/s 15, junio 2010, pp. 221-234 
ser con necesidades, deseos y afectos concretos, pero que lo que constituye su dignidad moral no es lo que nos diferencia a unos de otros, sino más bien lo que nosotros, en tanto que agentes racionales que hablan y actúan, tenemos en común. Nuestra relación con el otro es regida por las normas de igualdad formal y reciprocidad cada cual tiene el derecho a esperar y suponer de nosotros lo que nosotros podemos esperar o suponer de él o de ella [...] El punto de vista del otro concreto, por el contrario, nos demanda considerar a todos y cada uno de los seres racionales como un individuo con una historia, una identidad y una constitución afectivo-emocional concretas. Al asumir este punto de vista hacemos abstracción de lo que constituye lo común. Intentamos comprender las necesidades del otro, sus motivaciones, qué busca y cuáles son sus deseos. Nuestra relación con el otro es regida por las normas de equidad y reciprocidad complementaria, cada cual tiene el derecho a esperar y suponer de los otros formas de conducta por las que el otro se sienta reconocido y confirmado en tanto que ser individual y concreto con necesidades, talentos y capacidades específicas ${ }^{22}$.

Así, la perspectiva del «yo concreto» que propone Benhabib, trata de poner de relieve las particularidades que nos diferencian. Las relaciones con el otro se fundamentan en la equidad y la reciprocidad complementaria; son normas propias de prácticas privadas como la amistad o el amor, donde el trato tiene en cuenta las necesidades del sujeto concreto. Las categorías morales que interactúan en este proyecto son: la responsabilidad, el vínculo y la empatía; y los sentimientos morales que las sustentan: el amor, el cuidado, la simpatía y la solidaridad. Es un proyecto bello que conlleva ciertas dosis de utopía, que Benhabib conoce, pues no pretende fundamentar sobre esto una teoría política, busca poner de relieve la insuficiencia del «yo generalizado» de la teoría de Rawls. Cierto que la teoría moral y el punto de vista moral rawlsiano evita que se contaminen de principios reivindicativos sexistas, racistas o culturalistas y sólo ella es capaz de integrar la complejidad y el pluralismo de las sociedades contemporáneas. Quizás la solución sería «una teoría moral que nos permita reconocer la dignidad del otro generalizado mediante el reconocimiento de la identidad moral del otro concreto ${ }^{23}$, pero ¿cómo se hace esto? ... Bajando el hipotético agente moral idealizado al suelo del diálogo real de los agentes morales que se comunican entre sí. De nuevo volviendo a Habermas y su propuesta de una democracia radical, deliberativa y abierta, basada en las reglas del juego del diálogo.

Curiosamente la polémica igualdad/diferencia llega a la misma aporía. «La mujer», en sentido genérico, sin duda tiene el mismo problema que todos

22. BENHABID, Seyla. Op. cit., p. 136.

23. VALLESPín, Fernando. Op. cit.

Feminismo/s 15, junio 2010, pp. 221-234 
los conceptos que ya hemos mencionado, como el sujeto trascendental kantiano, el individuo universal o el punto de vista moral, todos hacen abstracción de las particularidades. Pero este es el precio que se ha de pagar por la visibilidad en el espacio público, las particularidades y las diferencias no suman, disgregan.

Precisamente una aspecto importante en esta polémica, viene de la mano de distinguir entre igualdad e identidad. Las feministas de la igualdad insisten en que no hay que tomar ambos conceptos como sinónimos:

Si hacemos justicia al concepto de igualdad en su raíz histórica en la Ilustración este uso no es tan estipulativo: tiene un fundamento histórico. Utilizaremos el concepto de igualdad en este sentido ilustrado, en el que igualdad no es para nada sinónimo de identidad. Hablamos de identidad cuando nos referimos a un conjunto de términos indiscernibles que comparten una predicación común [...] Sin embargo, cuando hablamos de igualdad nos referimos a una relación de homologación bajo un mismo parámetro que determina un mismo rango, una misma equiparación de sujetos que son perfectamente discernibles ${ }^{24}$.

La igualdad en este sentido es un valor, es algo que se tiene que construir, pertenece al nomos, a las leyes, es un valor regulativo, normativo. La diferencia, en cambio, viene dada, se da en la vida humana, pertenece a la physis, naturaleza, y hay todo tipo de diferencias pues la naturaleza es múltiple, diferencias genéricas, sociales, étnicas, raciales e individuales. Se trata de dos ámbitos irreductibles, por ello el reconocimiento de las diferencias pasa por ponerlas en el mismo rango, que mi diferencia se vea reconocida exige un principio normativo que la legitime como igual a otras diferencias, y en esto consiste la igualdad.

\section{Referencias bibliográficas}

Adorno, Theodor y Horkheimer, Max. Dialéctica de la Ilustración. Fragmentos filosóficos. Madrid, Trotta, 1998.

Amorós, Celia. La gran diferencia y sus pequeñas consecuencias... para la lucha de las mujeres. Madrid, Cátedra, 2006.

BEauvoir, Simone de. El segundo sexo. Buenos Aires, Siglo XX, 1977.

Benhabib, Seyla. y CoRnella, Drucilla. Teoría feminista y teoría crítica. Valencia, Edicions Alfons el Magnánim, 1990.

24. Amorós, Celia. La gran diferencia y sus pequeñas consecuencias... para la lucha de las mujeres. Madrid, Cátedra, 2006, p. 287.

Feminismo/s 15, junio 2010, pp. 221-234 
BUTLER, Judith. «Variaciones sobre sexo y género. Beauvoir, Wittig y Foucault». En Benhabib Seyla y Cornella Drucilla, Teoría feminista y teoría crítica. Valencia, Edicions Alfons el Magnánim, 1990.

Butler, Judith. Género en disputa. El feminismo y la subversión de la identidad. Barcelona, Paidós, 2001.

Castells, Carme. (coord.). Perspectivas feministas en teoría política. Barcelona, Paidós, 1996.

Delphy, Christine. «El principal enemigo». En Por un feminismo materialista y otros textos. Barcelona, Edicions de les Dones, 1982.

DURÁN, Ma Ángeles. (ed.). Las bases sociales de la economía española. Valencia, Universidad de Valencia, 1997.

FraSeR, Nancy. «¿Qué tiene de crítica la teoría crítica?» en Benhabib, Seyla y Cornella, Drucilla, Teoría feminista y teoría crítica. Valencia, Edicions Alfons el Magnánim, 1990.

Habermas, Jürgen. Teoría de la acción comunicativa. Madrid, Taurus, 1987.

HABERMAS, Jürgen. Historia y crítica de la opinión pública. Barcelona, Editorial G. Gili, 1999.

HABERMAS, Jürgen. Facticidad y validez. Sobre el derecho y el Estado democrático de derecho en términos de teoría del discurso. Madrid, Trotta, 2005.

IZQUiERdo, Ma Jesús. El malestar en la desigualdad. Madrid, Cátedra, 1998.

Mate, Manuel Reyes. Pensar la igualdad y la diferencia. Madrid, Visor, 1995.

PATEMAN, Carole. El contrato sexual. Barcelona, Anthropos, 1995.

PATEMAN, Carole. «Críticas feministas a la dicotomía público/privado». En Castells, Carme (coord.), Perspectivas feministas en teoría política. Barcelona, Paidós, 1996.

Rhode, Deborah L.. Justice and Gender. Cambridge Mass. Harvard University Press, 1989.

VALlESPín, Fernando. «Igualdad y diferencia». En Mate, Manuel Reyes (coord.), Pensar la igualdad y la diferencia. Madrid, Ed. Visor, 1995.

Young, Iris Marion. «Imparcialidad y lo cívico público». En Benhabib, Seyla y Cornella, Drucilla, Teoría feminista y teoría crítica. Valencia, Edicions Alfons el Magnánim, 1990. 